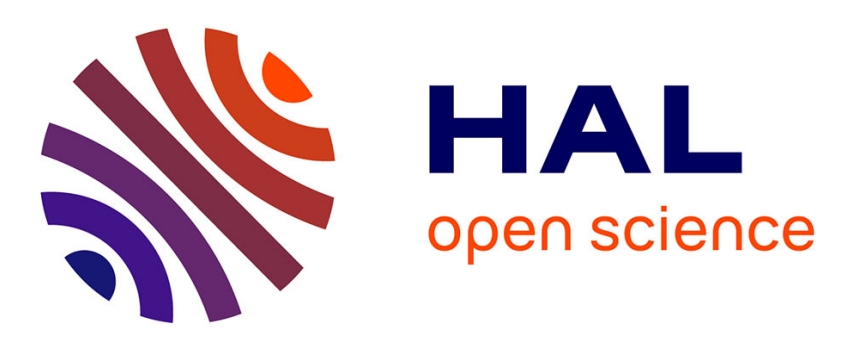

\title{
Fighting Crime: Harnessing the Power of Virtual Social Communities
}

Marie J. Hattingh, Sunet Eybers

\section{To cite this version:}

Marie J. Hattingh, Sunet Eybers. Fighting Crime: Harnessing the Power of Virtual Social Communities. 18th Conference on e-Business, e-Services and e-Society (I3E), Sep 2019, Trondheim, Norway. pp.797-808, 10.1007/978-3-030-29374-1_65. hal-02510133

\section{HAL Id: hal-02510133 \\ https://hal.inria.fr/hal-02510133}

Submitted on 17 Mar 2020

HAL is a multi-disciplinary open access archive for the deposit and dissemination of scientific research documents, whether they are published or not. The documents may come from teaching and research institutions in France or abroad, or from public or private research centers.
L'archive ouverte pluridisciplinaire HAL, est destinée au dépôt et à la diffusion de documents scientifiques de niveau recherche, publiés ou non, émanant des établissements d'enseignement et de recherche français ou étrangers, des laboratoires publics ou privés. 


\title{
Fighting crime: Harnessing the power of virtual social communities
}

\author{
M.J. Hattingh [0000-0003-1121-8892] and S. Eybers ${ }^{[0000-0002-0545-3688]}$ \\ University of Pretoria, Private Bag X20, Hatfield, 0028, \\ marie.hattingh@up.ac.za, sunet.eybers@up.ac.za
}

\begin{abstract}
Crime is a reality that effects everyone in the world. Even developed countries such as the United Kingdom, Canada and Germany are not exempted from crime occurrences. Although these indicators are substantially less than developing countries such as South Africa, the existence of crime is a worldwide phenomenon. In this paper we explore the extent to which social media, in particular Facebook are used in the fight against crime.

The study adopts a social technical approach in its investigation, considering the symbiotic relationship between communities (the organisation), Facebook and the utilisation of Facebook to complete tasks (technical subsystem), team members and structure to report crime in virtual communities (social subsystem) and current governance structures (environmental system). Based on a study of 297 crime fighting Facebook communities in South Africa, we found a positive correlation between the number of Facebook crime fighting communities per region and the crime rates for a particular region. Furthermore, we noticed that the regions with the most crime communities also had the most Internet connectivity per household. Both findings are indicative of a functional symbiotic relationship between the technical subsystem and the social subsystem. However, it highlights the fact that these structures are initiated by communities therefore lacking strong intervention from the environmental system, in this instance governmental bodies. We propose that governmental agencies formally recognise social media platforms as social crime fighting tool. Secondly, we suggest that governmental entities should focus on infrastructure related challenges as part of their attempt to combat crime.
\end{abstract}

Keywords: Social Media, Crime Prevention, Facebook, Cohesive Community.

\section{$1 \quad$ Introduction}

Crime is a reality that affects everyone in the world, irrespective of their developmental classification status. Although a substantial difference between the number of crime occurrences and crime type exist between countries from different developmental classifications, the fact remains that crime occur. For example, when violent crimes (such as murder) are investigated, a country such as South Africa is listed as having three cities in the top 50 in 2017/2018 [1]. On the other hand, developed countries such as United Kingdom, Canada or Germany do not appear on the list. 
In a developing country such as South Africa, local authorities have called for local communities to work together to actively participate to combat crime. After the release of the 2014/2015 crime statistics the local Police Minister, Nkosinathi Nhleko, said that businesses, communities and the police need to work together to curtail crime in South Africa [2]. This call is a repeat of an earlier call by the Member of the Executive Council (MEC), Nomusa Dube-Ncube, who expressed his shock at the brutal killing of one of its members [3]. He stated that "It is incidents such as this heinous crime that remind us that crime and violence remain a grave challenge in our communities and that as society we need to galvanise each other's strength to isolate the criminal elements that threaten social cohesion and harmony in our communities" [3].

Communities have been 'taking up the fight' against crime in the form of Social Networking Crime Fighting communities - specifically Facebook. These "crime fighting communities" were established with the specific purpose to combat crime in the area. In [4] it was reported how a CPF uses Facebook to execute their mandate and found that the CPF community shares two types of information: firstly information relating to the building of a cohesive community. Secondly, information related to the creating of awareness of crime in the area. In a second study [5] investigated how Facebook is used to locate people who have been reported missing by family or friends in South Africa. Graphs were used to indicate differentiated roles of the Facebook communities. Whilst some communities act mainly as originators of the messages, others act more as distributors or end points of the messages.

On an international level similar studies, where communities act both as originators and distributors of messages to contribute to a specific cause, have been conducted. One such instance was the utilisation of a Facebook group to assist with the finding of an Australian woman, Gillian "Jill" Meagher that went missing after an evening out. Although the study reported on the "collective practices of meaning-making in response to public crime events" [6], it was a good example of how Facebook communities were utilised. This is in line with the findings of Hattingh [4] and Powell et al. [6] that confirms that social networking sites, such as Facebook, are used in the fight against crime and crime related activities.

This paper will extend on previous studies by answering questions regarding the representation and focus of communities on Facebook and the probable correlation between said communities and crime levels. The study will furthermore add to the existing understanding of the use of technology and community participation in the fight against crime in developing countries. This will be achieved through a structured review (using specific keywords) of Facebook communities/groups. The study is based on a sociotechnical approach as the main theoretical underpinning considering the assumed symbiotic relationship between communities (the organisation), Facebook and utilization of the Facebook environment to complete tasks (technical subsystem), team members and structure in the virtual community (social subsystem) and current governance structures (the environment). This will hopefully expose the weak points in the socio-technical value chain.

The remainder of the paper follows the following structure: in section 2 we provide an introduction to the socio-technical theory [7]. In section 3 the literature will be presented in accordance with the socio-technical theory introducing the environment, the 
organizational system and the social and technical subsystems. The approach to this study is discussed in section 4 where after we discuss the results in section 5 . We conclude the study in section 6 .

\section{Social Technical Theory}

Socio-technical theory focus on the interrelationship between technical subsystems and social subsystems with the main objective of creating a balanced, effective, symbiotic relationship in the context of an organisation or social system governed by the rules and regulations of a bigger environmental system [7]. It is postulated that, the more effective the interrelationship, the greater the benefits as a result of the interaction between the subsystems [7]. Socio-technical systems refer to the interaction between team members in a social system or organisation whilst the technical system refers to the utilisation of technical tools and techniques that enable the interaction (referred to as tasks) [7].

In the instance of Facebook communities, the organisation sub system refers to a virtual community, i.e. CPF in Facebook. The community interacts within the virtual community through the utilisation of Facebook, in this instance the social networking site (or Web 2.0 tool) [8] enabling connectivity and information sharing amongst members. The virtual community share the same values, i.e. to contribute to a safer community through collaboration. These values are built into the use and capabilities of technology (the technical subsystem). For example, strict security measures by means of membership only groups can be enforced in order to vet members for membership eligibility prior to joining the group. As a result, potential members with criminal intent is identified prior to the allowing membership.

This virtual FB community is a classic example of a self-organising community [9] with a shared interest of contributing to a safer local community. The environmental system provides the overall governance and unspoken rules to the other systems/subsystems (organisation, technical and social). For example, the prevention and possible prosecution of 'hate speech' when using the virtual community is governed by the inherent rules and regulations of the local government.

\section{The Organisational System: Cohesive Communities}

The causes, impact and response to crime as well as the relationship between these factors have been a much researched area internationally [10-12]. One study of much importance is research conducted by Leverentz and Williams [10] that investigated how physical communities react to, and subsequently attempt to control crime by adopting various crime-control strategies. They have identified three responses or strategies to crime namely "reliance on public alliances, tentative public-parochial partners and grassroots public engagement". Bendler et al [13] has investigated the utilisation of social media data (Twitter) to predict crime related activities using predictive analysis and virtually published their results as part of a "virtual neighborhood watch" group. 
Using predictive analysis to predict crime based on historic events are perceived by many authors as key to combat future crime.

Research on the impact of crime in South Africa has increased significantly, particularly with publications such as this one, dedicated to report on the state of, and the progress in the fight against crime in South Africa. Crime patterns are not evenly distributed which makes it difficult to predict and manage [14]. Recent statistics indicated that the Western Cape has the highest level of reported crime experience at 9.7\%, followed by Gauteng with $9.1 \%$. The lowest level of reported crime experienced was in Limpopo with $4.2 \%$. There has been a focus on two main areas in the fight against crime: Cohesive community participation and the use of technology. A cohesive community is defined as a community where "there is a common vision and sense of belonging for all communities, the diversity of people's different backgrounds and circumstances is appreciated and positively valued" [15]. The cohesive community is also referred to as the organisation in the social-technical theory, whilst the use of technology forms part of the technical subsystem. In the sections to follow each of these two areas or subsystems will be elaborated upon. However, first the environment in which these two subsystems exist need to be considered and will be discussed next.

\subsection{Environment: Governance Structures.}

Any community initiative needs to occur within the confines of the law. This include community initiatives that support the fight of crime. In support of the CPF initiative of the SAPS, Choi, Lee and Chun [16] state that the police force (the environmental system) needed the support of communities in order to be effective in providing community safety. In their extensive literature survey they identify a number of factors that motivate citizens to participate in crime prevention activities: (1) confidence in the police, (2) personal safety, (3) attachment to the area, and (4) crime problems in the community.

The importance of CPFs are further highlighted in research by Rey [17] where the author focused on the identification and measuring of online crime prevention communities to ensure the healthy (and therefore effective) only communities.

Even though the South African Police Service (SAPS) has a social media presence, the platforms are only used to engage with citizens. They urge citizens not to use social media platforms to report a crime as the type of information required (normally by an operator) is too specific and the response time to these posts cannot be guaranteed [18].

\subsection{Social subsystem: Using Cohesive Communities to Combat Crime.}

Sampson and Raudenbush [15] found that cohesive communities display lower levels of crime and social disorder due to the collective effort by the community to meet their common goal. Lee [19] found that socioeconomic status, lifestyle and neighborhood characteristics have no influence on the possibility of be-coming a victim of violent crime, such as robbery and assault, when one is part of a cohesive community because 
of high levels of social control. Even though Roberts and Gordon and Gordon [12] found that social cohesion can pull citizens apart due to the fear of crime, it was found in a previous study [4] that community cohesion had a positive effect on the community. This was also supported by an earlier study conducted by Wedlock [11] found that there was a $3 \%$ decrease in residential burglary, $4 \%$ decrease in motor theft, $2 \%$ decrease in theft from motor vehicles and 3\% decrease in violent crime with every $1 \%$ increase of sense of community experienced by neighborhood communities.

\subsection{Technical subsystem: Using Technology to Analyse and Predict Crime.}

The use of technology in the fight against crime can take two forms: using technology in the analysis of crime statistics and using it to predict the possibility of crime occurrence. Firstly an example of the former is the interactive crime statistics map(s) based on the annual crime statistics released by the SAPS and created by the Institute for Security Studies. The visual representation of the SAPS crime statistics allow citizens to view the crime trends since 2004 per category, per municipality and per police station. In addition to the SAPS' statistics the Crime Hub provides information on public violence per region [20].

Secondly technology allows for the prediction of crime. Cherian and Dawson [21] employed machine learning and other statistical techniques to classify and predict average crime incidents in the coming weeks and months. Also, the illustrative study of Lancaster and Kamman [22] proposed a data linking methodology that can analyse the demographic characteristics of police precincts to predict the murder rate at precinct level. This methodology allows for more sophisticated measurements to investigate certain associations between the risk factors identified in the ecological framework (consisting of the individual, relationship, community and societal). One of the most important indicators that could be identified using this methodology will be that between crime and the community which includes "feelings of belonging or perceptions of social or group integration, and a willingness to show solidarity". This connects the "technology" aspect to the community aspect.

The previous discussions have considered community participation independent of the usage of technology to combat crime. Web 2.0 technologies and more specifically social networking platforms allows normal citizens to partake of the content creation platforms, especially in the form of social networking participation. In the following section we will discuss how communities utilize Web 2.0 technologies to combat crime.

\subsection{Interaction between social and technical subsystems: Communities using Web 2.0 technology to combat crime.}

The increased Internet access of South Africans have enabled more citizens to take part in digital activities. According to World Wide Worx and Ornico's South African Social Media Landscape 2018 study there has been a sharp increase in social media uptake. $31 \%$ (16.74 million) of all South Africans now use WhatsApp and 26\% (14.04 million) 
of all South Africans use Facebook [8]. Social networking platforms such as Facebook provide an ideal tool for citizens to participate in the fight against crime. Citizens can now "post" about an event or upload photos and videos with GPS coordinates without much effort. The most prominent use of social media in the fight against crime was during the Boston Marathon bombings where it was used to identify the bombers successfully. In response to this successful use of social media McCullagh [23] stated that "a traditional manhunt becomes something much different in the age of Twitter, Instagram, and face recognition".

Twitter has been used in the fight against crime. Wang, Gerber and Brown [24] developed a model that predicts hit-and-run incidents uniformly across all days. Bendler, Brandt, Wagner, and Neuman's [13] research focused on how Twitter can be used to create a sort of virtual neighborhood watch (NHW) which will create a secure environment for tourists and residents. It will also help the police and authorities in identifying patrol spots. The latter is accomplished through the live prediction from media streams. Gerber [25] further analysed the use of Twitter to predict crime by analysing the tweets using kernel density estimation. He identified a number of "performance bottlenecks" that could have an impact on the use of Twitter in an actual decision support system.

In South Africa Featherstone [26] investigated how Twitter can make communication more useful in terms of data gathering, prediction and plotting broader patterns. She showed in a second paper how Twitter can be used to identify vehicle descriptions to assist in reducing or predicting crime [27].

In [14] the Internet access at home, at work, using mobile devices and at other facilities were reported. It should be noted that a citizen can access the Internet at more than one location, therefore the total percentage of Internet access can exceed 100\%. Taking this into account, Gauteng has the highest level of Internet access with $119.7 \%$ followed by Western Cape with 113\%, Kwa-Zulu Natal with 76.7\%, Free State with $75.4 \%$, Mpumalanga with $75.1 \%$, Northern Cape with $73.4 \%$, Eastern Cape with $69 \%$, North West with $67.7 \%$ and Limpopo with lowest level of access at $49.4 \%$.

Mobile Internet access is by far the most accessible option of accessing the Internet as it can happen anytime, anywhere. This is not surprising as currently there are 20.8 million smart phone users in South Africa [28].

\section{$4 \quad$ Research Methodology}

The aim of this research project is to explore the extent to which communities fight crime using Facebook groups/pages as part of a bigger socio-technical system. In reaching the aim the following questions need to be answered: (1) To what extent are crime fighting communities represented on Facebook? (2) What is the focus of these communities? (3) Is there a correlation between the number of crime fighting Facebook communities, the membership rate of the crime fighting Facebook communities and the crime rate on provincial level? (4) What are the weak areas considering the various subsystems (organisation, technical, social and environmental) in the bigger socio-technical system? 
In answering the first research question the researchers conducted a review of Facebook communities between 22 March and 30 May 2016. Facebook's built-in search engine was used to search the following key words to identify "crime fighting communities" on Facebook: "CPF", "Community polic (to pick up "Policing" and "Police")", "Crime", "Concerned citizens", "Crisis", "Emergency", "Intelligence bureau", "Neighborhood watch". The search was restricted to South African groups/pages that were in English. The keywords were derived by following a snowball sampling approach, where the first keyword "CFP" derived from the first study [4] was used as the initial community. The researchers then observed which pages/groups were linked to the intitial community to derive the remaining keywords.

The researchers recorded, in an MS Excel spreadsheet, the keyword used in the search, whether it was a group or page, the title of the group/page, membership numbers, the description of the group/page, which province the group/page covered and whether mention was made of any other means of communication, like WhatsApp and interesting observations. The researchers also captured the latitude and longitude of each area obtained from the LatLong.net in the spreadsheet which helped them to plot all the Facebook communities that were identified through the search, on a map of South Africa. This map is generated by MS Excel Powerview and is illustrated in Figure 1. The size of the bubble is related to the number of communities in that particular area. The overlapping bubbles indicate the concentration of members in a specific area as an individual can be a member of more than one community and the number of communities in a very small area.

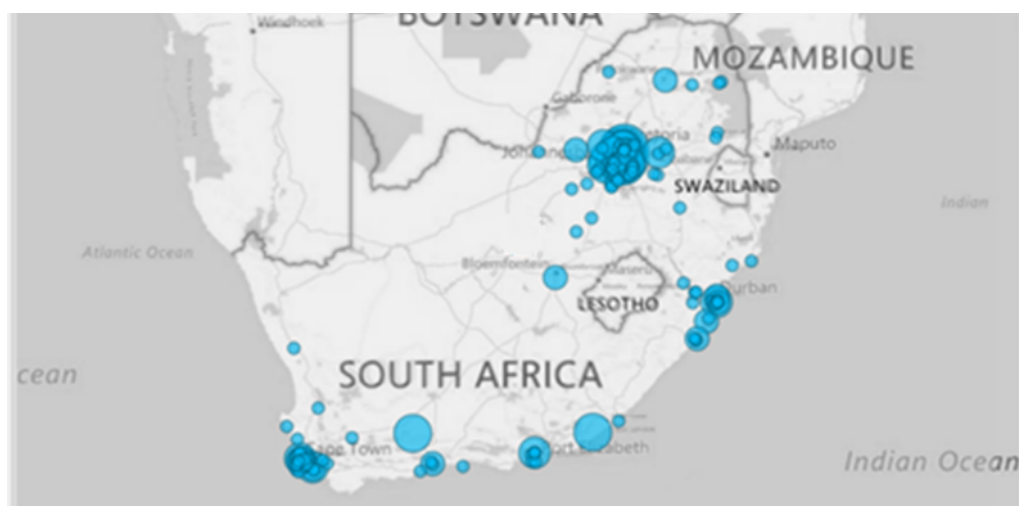

Fig. 1. Facebook communities in South Africa

In order to answer the second research question thematic content analysis [26] was used to analyse the descriptions (as stated on their Facebook profiles) of the top member groups, as well as all the posts for the past week (6 July 2016 - 13 July 2016) which will be used to obtain an understanding of the focus of each group/page. In order to answer the third research question the researchers utilised the results illustrated in Figure 1. No further data was gathered to answer the fourth research question as data gathered to answer question one to three will be used to apply to the concept of a sociotechnical system. 


\section{$5 \quad$ Discussion of Results}

The aim of this paper was four-fold: firstly, to identify the number of crime fighting communities on Facebook in South Africa, secondly to understand the focus of said communities thirdly to determine if there is any correlation between the communities and the crime levels and fourthly to use the data gathered in order to identify possible weak links in the various subsystems of the socio-technical system. The results will be discussed in accordance with these question.

\subsection{The number of "crime fighting communities" on Facebook in SA}

In meeting the first aim, the Facebook search, using the keywords stated above, have revealed 297 dedicated crime fighting Facebook communities throughout South Africa. The Eastern Cape has 18 communities (91 364 members), Free State has 7 communities (12 645 members), Gauteng has 114 communities (299 336 members), Kwa Zulu Natal has 29 communities (65935 members), Mpumalanga has 10 communities (16 884 members), North West has 11 communities (23 44 members), Western Cape has 71 communities (153 712 members) and Limpopo has 6 communities (3820 members). Furthermore, there were 31 national communities which are not associated with any specific area/province. In total more than 1.1 million in South Africans belong to crime fighting communities. (It is possible for a citizen to belong to more than one community simultaneously). The communities considered is by no means an exhaustive list of crime fighting communities, it was observed that a number of the communities also had websites, WhatsApp groups, Zello accounts, Twitter accounts or use "old fashioned" citizen band radios. The usage of multiple (mainly) social media platforms by the communities are in line with a previous study by Hattingh [4] where a single CPF used multiple platforms.

Although the number of communities dedicated to crime in SA was impressive the most interesting finding of this study is that, by using the keyword listed previously, no Facebook crime fighting communities were found for the Northern Cape Province.

\subsection{The focus of the "crime fighting" Facebook communities}

Facebook Communities typically had a description that invites community members to partake in the fight against crime. From the quotes below, it can be seen that these communities were dedicated to "fighting crime".

"Reporting and fighting crime - by the community for the community" [Concerned Citizens page, GP]

Communities are now standing together to make headway in the fight against crime by supporting one another. The following post illustrates the call from the community for the community to assist.

"The Time Has Come.......we have to all pull together and watch over each Other. Crime is out of hand and out of touch. Everyone needs an immediate update of Crime and emergencies in your Area, so that anyone in the Vicinity can Respond and assist immediately, like all Good and caring Citizens should. ..." [Crime group, KZN] 
In addition to identifying the "mission" of each Facebook community by reviewing their descriptions, a total of 210 posts were reviewed across the top five communities. The analysis have generated a number of themes which supported those that have been identified in a previous study [4] which included "reporting", "awareness", "alertness", and "update". The cohesive community principle of cohesive community as introduced in [4] was extended by requesting "assistance" from the community members. For example, community input was requested on a vehicle accident that occurred (assistance theme), general information regarding awareness tips (awareness theme), information sharing regarding activities in the community to "Be On the LookOut" (BOLO) for armed robbery suspects, missing people, suspects involved with a murder/robber/vehicle theft etc. (alertness theme). The reporting and updating activities in followed in the same vein as previous studies. However, there have been much more updates provided to the community members compared to the first study. $12 \%$ of the posts were updates to "crime events" that occurred. This includes updates regarding armed robberies, vehicle theft, ATM bombings etc. Research has shown that updates are important and seen as "rewards" for communities when communities help by providing the intelligence when solving a problem [4].

The data revealed a few more crime categories identified compared to the first study. This includes posts related to drugs which includes updates on successful drug busts but also awareness regarding the dangers of using drugs and who to contact when help is needed with regards to rehabilitation. Furthermore, hi-jacking's, ATM bombing and public violence/protests were the other new crime categories that were identified. The new crime categories can be a result of firstly, the larger "affected area" as three of the five groups under consideration were "National groups" (i.e. not related to a specific area) and secondly due to the time the snapshot of posts were taken - just before the government elections.

Finally, even though three of the five groups were "National", the theme of cohesive community, identified in the previous study persist as there were 73 information sharing posts which included posts with photos/videos/newspaper articles on incidents such as drug busts, substation being on fire, road collisions that happened in the past week etc. These posts were not updates per say (an update is defined as a response to a specific incident) but it kept the communities informed about activities in their area/surrounding areas.

\subsection{Correlation between the communities and the crime levels}

When comparing the number of communities to the crime statistics as presented above, it shows that Limpopo province has the lowest level of experienced crime events [14]. Limpopo only has six crime fighting communities with a mere 3820 members in total. With a population of more than 5.72 million [14] people the Facebook crime fighting communities are only accounting for $0.0007 \%$ of the population of Limpopo. One reason for this might be that Limpopo has the lowest Internet access level of $49.4 \%$ [14].

On the opposite end of the scale, Gauteng, the smallest province have a total of 114 different crime fighting Facebook communities, with a total membership of more than 
299 000. Gauteng also has the second highest experienced crime level and has the largest Internet access level. The high crime rate, high population and high Internet access level might explain why Gauteng has by far the most crime fighting communities on Facebook, in South Africa. It can therefore be argued that there is a correlation between the crime levels, the number of social media crime fighting communities and to a lesser extent the availability of Internet access in the province.

\subsection{Possible weak links in the various subsystems of the socio-technical system}

Based on the discussion above it is therefore evident, and safe to say, that the organisation system is a strong, functional subsystem although it was anticipated that a stronger focus on the objective of crime fighting would prevail. The majority of the communities work together with the SAPS and security companies (as illustrated in the quote below) in the fight against crime.

"Independent Group to report Crime, creating a vigilant community helping each other bringing the Community, Police, Sector Police and Security companies together in fighting crime". [Crime group, WC].

Figure 2 illustrates the socio-technical system of crime fighting communities on Facebook.

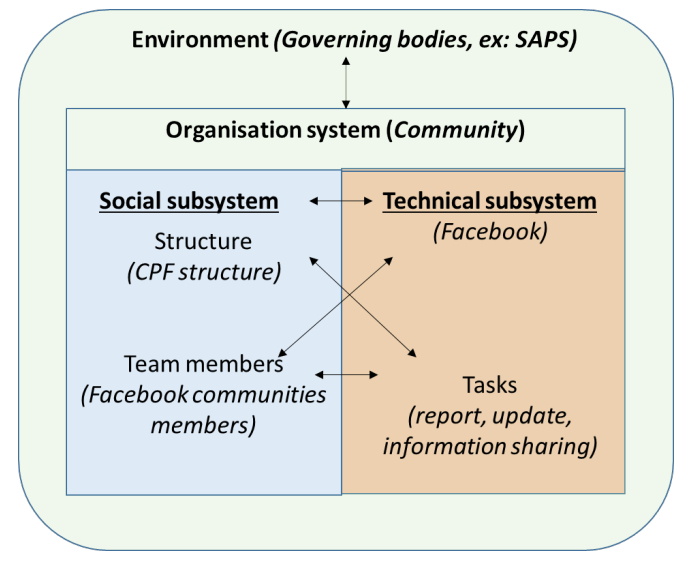

Fig. 2. Facebook as a socio-technical used by crime fighting communities

However, the utilisation of the technical subsystem by means of a computer mediated communication platform (Facebook) has enabled members to contribute to a greater, common cause despite geographical dispersed challenges.

The technical subsystem, (the social media platform, in this instance Face-book), is an effective tool to use in the fight against crime. Internationally social media platforms are used as a crime prevention tool [29]. Citizens of South Arica, through the utilization of Facebook Communities and other social media platforms have already showed a willingness to work with the SAPS and other security organisations, however the impression is that this initiative is driven from the citizens' side. The environmental system (SAPS and other governmental institutions) perhaps need to formally recognize the 
potential of social media as a crime fighting tool and dedicate resources to assist citizens in the monitoring of social media crime reports and deploy the necessary members to act on these reports. If this issue can be addressed it can contribute to a stronger environmental subsystem to the benefit of the organisation subsystem. Social media platforms or the technical subsystem is an inexpensive medium to formulate a crime fighting network.

\section{Conclusion}

This paper has confirmed and extended previous findings on the successful use of Facebook as a crime fighting tool by communities in South Africa. The paper has found that 297 Facebook communities, over eight provinces, exist that are dedicated to the fight against crime. The findings indicated a correlation between the number of crime communities and crime rates. As the power of social media as a crime fighting and prevention tool has been confirmed in this study and previous studies, it is recommend that the SAPS formally recognise and adopt social media platforms as a crime fighting and prevention tool. Government needs to develop a formal strategy, incorporating all relevant departments, to enable citizens through the provision of affordable data and infrastructure to participate in the fight against crime. It is envisaged that, if these challenges are addressed, the environmental subsystem, which have been identified as a weak link, will contributed to a stronger, much more effective socio-technical system.

\section{$7 \quad$ References}

1. Cape Town is one of the most violent cities in the world [Internet]. BusinessTech. 2018 [cited 2018 Mar 31]. Available from: https://businesstech.co.za/news/lifestyle/230123/capetown-is-one-of-the-most-violent-cities-in-the-world/

2. Police and communities must fight crime together [Internet]. North Natal Courier. 2015 [cited 2018 Mar 5]. Available from: https://northernnatalcourier.co.za/30679/speaker-shooting-mec-condemns-brutal-murder/

3. South African Government. MEC Nomusa Dube-Ncube condemns the brutal murder of Councillor Vusi Ntombela. South African Government. 2015.

4. Hattingh MJ. The use of Facebook by a Community Policing Forum to combat crime. Proc SAICSIT ' 15. 2015; 2 (2):1-10.

5. Hattingh MJ, Matthee MC. Using Facebook to find missing persons: A crowd-sourcing perspective. Vol. 9844, Lecture Notes in Computer Science. 2016.

6. Powell A, Overington C, Hamilton G. Following \#JillMeagher: Collective meaning-making in response to crime events via social media. Crime, Media, Cult An Int J. 2017; 174165901772127.

7. Bostrom RP, Heinen JS, Heinen JS. STS Perspective MIS Problems and Failures : A SocioTechnical Perspective Part I : The Causes By : Robert P. Bostrom. 2016; 1 (3):17-32.

8. World Wide Worx and Ornico. 2018 The Social Media Landscape in South Africa [Internet]. 2017 [cited 2018 Mar 2]. p. 2017. Available from: http://gullanandgullan.com/wp-content/uploads/2017/10/13907_GG-Breakthrough-infographic.pdf 
9. Starbird K., Palen, L.Self-Organizing by Digital Volunteers in Times of Crisis. In: 29th Annual CHI Conference on Human Factors in Computing Systems 2011 Proceedings.

10. Leverentz A, Williams M. Contextualizing Community Crime Control: Race, Geography, and Configurations of Control in Four Communities. Criminology. 2017;55 (1):112-36.

11. Wedlock E. Crime and cohesive communities. 2006. [cited 2018 Mar 2]. p. 2017. Available from: http://citeseerx.ist.psu.edu/viewdoc/download?doi=10.1.1.510.6857

12. Roberts B, Gordon S. Pulling us apart? The association between fear of crime and social cohesion in South Africa. South African Crime Q. 2016;(55):49-60.

13. Bendler J, Brandt T, Wagner S, Neumann D. Investigating Crime-To-Twitter Relationships in Urban Environments - Facilitating a Virtual Neighborhood Watch. Twenty Second Eur Conf Inf Syst. 2014;1-16.

14. Release S. General Household Survey 2016. 2018; (May). [cited 2018 Apr 2]. p. 2017. Available from: https://www.statssa.gov.za/publications/P0318/P03182016.pdf

15. Sampson RJ, Raudenbush SW, Earls F. Neighborhoods and violent crime: a multilevel study of collective efficacy. Science (80- ). 1997; 277(5328):918-24.

16. Choi K, Lee J, Chun Y. Why Do Citizens Participate in Community Crime Prevention Activities? 2014; 287-98.

17. Rey PJ. Defining and Measuring Success for Online Crime- Prevention Communities. In: AMCIS 2011 Proceedings - All Submissions. 2011.

18. SAPS. Services | SAPS (South African Police Service) [Internet]. [cited 2018 Mar 24]. Available from: https://www.saps.gov.za/faqdetail.php?fid=13

19. Lee MR. Community cohesion and violent predatory Victimization: A theoretical extension and cross-national test of opportunity theory', Social Forces, pp. doi: 10.1093/sf/79.2.683. 2000; 79:683-706.

20. Institute for Security Studies [Internet]. 2016 [cited 2016 Jul 11]. Available from: https://www.issafrica.org/crimehub/

21. Cherian J, Dawson M. RoboCop : Crime Classification and Prediction in San Francisco. $2014 ; 2014$

22. Lancaster L, Kamman E. Risky localities: Exploring a methodology for measuring socioeconomic characteristics of high murder areas. South African Crime Quarterly; No 56 June 2016 Ed - 1017159/2413-3108/2016/v0i56a51. 2016 Jun 28;

23. Men! F seeks crowdsourcing help in B bombing case: I these two. McCullagh, C. [Internet]. CNET. 2013 [cited 2018 Mar 25. Available from: https://www.cnet.com/news/fbi-seekscrowdsourcing-help-in-boston-bombing-case-id-these-two-men/

24. Wang X, Gerber MS, Brown DE. Automatic crime prediction using events extracted from twitter posts. Lect Notes Comput Sci. 2012;7227 LNCS:231-8.

25. Gerber MS. Predicting crime using Twitter and kernel density estimation. Decis Support Syst. 2014;61(1):115-25.

26. Featherstone $\mathrm{C}$. The relevance of social media as it applies in South Africa to crime prediction. Inst Electr Electron Eng. 2013; 1-7.

27. Featherstone C. Identifying vehicle descriptions in microblogging text with the aim of reducing or predicting crime. IEEE Int Conf Adapt Sci Technol ICAST. 2013;

28. Number of smartphone users in South Africa from 2014 to 2022 (in millions) [Internet]. Statista. 2018 [cited 2018 Apr 2]. Available from: https://www.statista.com/statistics/488376/forecast-of-smartphone-users-in-south-africa/

29. United Nation. The Role of the Public in Strengthening Crime Prevention and Criminal Justice. In: 13th United Nation Congress on Crime Prevention and Criminal Justice. 2015. p. 2. 